\title{
Surgical Management of Nasal Hemangiomas
}

\author{
Aleksandar Vlahovic \\ Plastic, Aesthetic and Reconstructive Surgery, Belgrade \\ Serbia
}

\section{Introduction}

Vascular anomalies are seen in all branches of medicine and surgery. The term vascular anomaly is necessarily broad, encompassing lesions of skin and viscera and excluding abnormalities of the heart and large arteries and veins [1]. A biologic classification of vascular anomalies described in 1982 by Mulliken and Glovacki, correlates the cellular features of vascular anomalies with clinical characteristics and natural history [1,2]. Vascular anomalies of infancy and childhood are divided into two major categories: 1) tumors (most being hemangiomas) and 2) vascular malformations [1].

The typical infantile hemangiomas (IHs) appears postnataly and evolve through 3 predictable stages: a rapidly proliferating stage (generally lasting 8 to 12 months), followed by prolonged involuting phase ( 1 to 7 years), entering the involuted phase characterized by fibrofatty residuum [1,3]. Early proliferative-stage hemangiomas are composed of welldefined, but noncapsulated, masses of plump endothelial cells and attendant pericytes that form small lumina containing erythrocytes. Even in early lesional stage, endothelium posses immunophenotypic and ultrastructural features of mature endothelium including immunoreactivity for CD31, CD 34, factor VIII- related antigen Ulex europeaus lectin I, VEcadherin, HLA-DR, and vimentin. GLUT 1 is specific and useful immunohistochemical marker for hemangiomas during all phases of these lesions [3]. The typical IHs appears postnatally, grows rapidly, and regresses slowly. The term congenital hemangioma was introduced to denote a vascular tumor that had grown to its maximum size at birth and does not exhibit accelerated postnatal growth. There are at least two major subgroups: rapidly involuting congenital hemangioma (RICH), and noninvoluting congenital hemangioma (NICH) [4].

Infantile hemangiomas (IHs), are the most common benign, soft tissue tumors of infancy which affect between 4 and $12 \%$ of all Caucasian $[1,5,6]$. The prevalence among Asians and black infants is considerably less [5]. There is a 3:1 predilection for the female sex, and they are weakly associated with prematurity [6-8]. The pathophysiologic mechanisms leading to endothelial cells proliferation and involution are poorly understood [6,7]. Current theories focus on progenitor cells, development field defects, placental involvement, derangement of angiogenesis and mutations in the cytokine regulatory pathway [6,7]. Involution coincides with increased apoptosis of endothelial and stromal cells [7].

Most IHs involve the head and neck (up to 60\%) [1]. Facial IHs are associated with parental reactions of disbelief and fear, particularly in the growth phase. Most parents expressed a desire to have the hemangioma removed before the children entered school. The strangers 
often raised the question of child abuse, and some parents indicated that their children try to hide their lesions from the other [8].

Clinical appearance allows differentiation between focal, indeterminate and segmental IHs. Size, location and subtype were major factors that predicted complications and need for treatment [9]. Focal type had a tumor-like appearance and a less common diffuse type had a segmental distribution pattern and plaquelike appearance. Segmental IHs exhibit worse prognosis with more complications (ulceration, airway obstruction) [5,9]. Although subglottic hemangiomas are rare, they are extremely dangerous due to their location and rapid growth during the proliferative phase. "Beard" distribution of hemangioma is highly suspected for subglottic localization of hemangioma [5,6,23].

Most IHs are small, harmless tumors that should be allowed to involute without treatment. Generally, treatment is instituted for complications within the IHs itself (such as ulceration, bleeding, infection), or impairments caused by the hemangioma (amblyopia, impaired breathing, feeding difficulties, heart failure), and the wait-and-see medical management policy for these hemangioma should be replaced by a more active approach. $[9,10]$. More than half of IHs will involute with a poor result and therefore required a corrective surgery [11]. Haggstrom et al. stated that $43 \%$ patients with a facial hemangioma received treatment of some kind [9].

The management of hemangioma is an area of great controversy [6]. Current options are conservative treatment (corticosteroids, interferons, hemiotherapy, propranolol), laser treatment, and surgical treatment [6,9-27]. Corticosteroids were generally accepted to be the first-line therapy for hemangiomas [6]. They can be used orally, intralesionally, intravenously or topically. Interferons were usually reserved for serious cases in which steroids were contraindicated, have failed, or in severe complications [12]. Unfortunately, severe neurotoxicity (spastic diplegia) was found to be severe adverse effect [6]. Antineoplastic agents were also successful in treatment of hemangioma, because of their proliferative nature (bleomycin, cyclophosphamide, vinristine) but this treatment should be reserved for infants with hemangioma demonstrating aggressive behavior characteristics [6]. A wide variety of lasers have been used with a broad range of results (pulse-dye, CO2). Externally-applied laser can penetrate only 1-2 $\mathrm{mm}$ into the dermis and therefore has a limited value for the treatment of hemangioma [1,6]. Embolisation, cryotherapy and compression had also been used $[6,12,16,30]$.

Recently propranolol proved itself effective in inducing regression of growing hemangioma. There are several reports confirming prompt response of hemangioma to propranolol with no major side effects $[23,25,28,29]$.

There are three questions regarding surgical intervention: 1) what are the indications, 2) when it should be done (timing) and 3) how it should be done [30]. Surgical excision of hemangioma has been usually performed by lenticular excision with a linear closure. This technique is useful in the eyelid, lip and neck region [30]. An alternative technique that does not have these disadvantages is the circular excision or by circular excision and with purse string closure which is now considered the first line technique at any stage of the tumors life cycle $[11,30]$.

In some children with extremely large hemangiomas, the vascularity of the lesion is also a significant anesthetic consideration. There is a need for particular attention to hemodynamic consideration with anesthesia and potential need for transfusion. Haemostatic squeezing suture around the hemangioma can be used prior to resection to avoid blood loss [23]. 


\section{Nasal hemangiomas}

Nasal hemangiomas are among the more distressing, if large, can cause a significant residual damage to the shape of the nose [6]. Due to their location, nasal hemangiomas are profoundly disturbing lesions both for patients and their families (Fig. 1). Hemangiomas involving the nose occur approximately $15,8 \%$ of facial hemangiomas [13]. The nasal tip is by far the most common site of nasal hemangiomas [11].
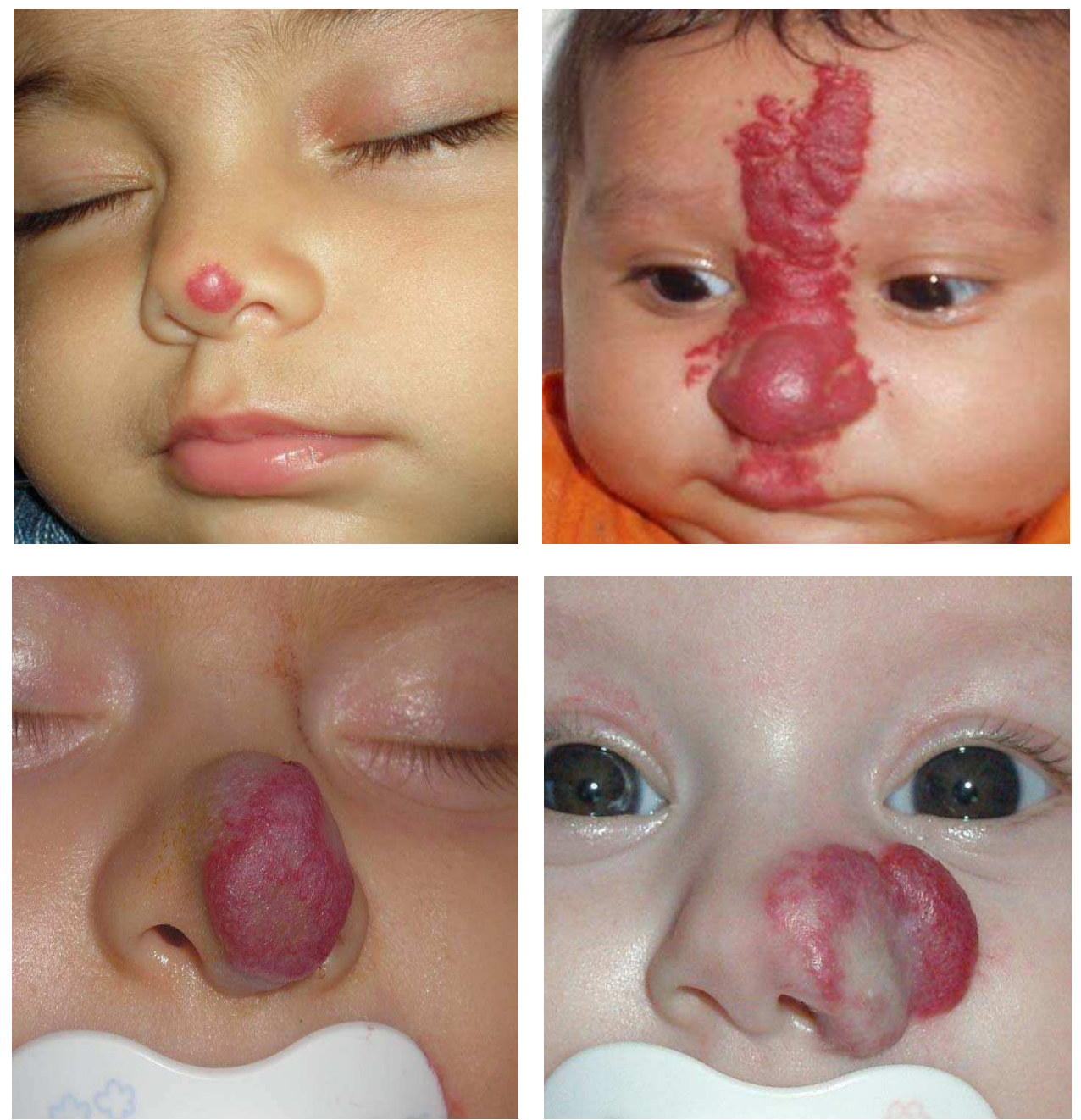

Fig. 1. Different types of nasal hemangioma from small no harming, involving nasal tip, complicated with nasal obstruction and large superficial hemangioma

Nasal hemangiomas can cause functional problems (nasal obstruction, alteration of the nasal valve, ulceration and destruction of the delicate growing cartilage of the nose) and severe psychological sequelae to the children because of social redicule of their peers, and also 
from medical professionals who are using terms like "Cyrano nose, "Pinocchio nose". During proliferative phase they can permanently distort nasal architecture (by displacing lower lateral cartilages laterally) [13-15,17]. Parent's anxiety is something that surgeon have to deal with during the child growth. In most cases they are not satisfied with explanation that hemangioma will regress spontaneously during childhood. Aesthetic problem is usually obvious. Eivazi et al. classified nasal tip hemangiomas as "limited" or "advanced" [25]. Hamou et al. identify three types of nasal hemangiomas that lead to three distinct surgical approaches:

- Type A (mild cases): no cutaneous involvement, no misalignment of the cartilages an mild nasal volume increase

- $\quad$ Type B (moderate cases): partial cutaneous infiltration, misalignment of the cartilages and moderate nasal volume increase

- $\quad$ Type C (severe cases): cutaneous infiltration, misalignment of the cartilages and severe nasal volume increase [31].

They are usually subcutaneous or mixed superficial and subcutaneous lesions that occupy the space between the skin and the nasal tip and lower lateral cartilages [15]. Nasal hemangioma are often slow to regress, leaving excess wrinkled nonelastic skin, residual fibrofatty tissue with a permanently bulbous nasal tip, visible teleangiectases or contour deficiencies $[11,13,14,17,19,20,27]$.

\section{Treatment options}

The treatment of nasal hemangiomas is extremely difficult because of its location and possible complications [31]. In most of these cases expectation is not a treatment option. There is a pressure from the family to improve the child's appearance.

Numerous medical and surgical treatment approaches have been proposed for the treatment of these tumors. The treatment choices of nasal hemangiomas are still controversial considering use of preoperative medical treatment, timing of surgery, surgical approach and necessity of skin resection [15, 27].

Pharmacological, surgical or laser interventions are current treatment options for nasal hemangiomas [13-27].

A "no-touch" or conservative approach for the treatment of nasal hemangiomas was previously advocated with frequent consultations with the parents to furnish psychological support [26].

Advocates of conservative treatment claim that resection causes growth disturbances in nasal architecture [14,16]. Denk et al. consider that conservative treatment should be reserved for small hemangiomas on the nose that are not deforming and are without complications [17]. Corticosteroids were, for the long period, the first line treatment for nasal hemangioma with excellent results in $30 \%$ of cases $[13,18]$. Interferon was usually reserved for life threatening lesions resistant to steroids [13]. Because of the possible complications (skin atrophy) Hochman and Mascareno have moved away from using local steroid injections for nasal hemangioma [22].

Because of convincing results, beta blockers are preferred as the first treatment option for proliferating hemangioma $[25,28,29,31]$. Proponents of early surgery suggest that aesthetic and functional improvement during a critical period in child development can be achieved [13-17]. 
Laser is indicated only for the treatment of the involuting hemangioma, and it is not helpful for the deeper components $[12,16]$.

\section{Surgical treatment}

Thomson et al. have been treated eleven patients with different surgical approaches. Several procedures had been carried out on each patient (an average of 4 operations on one patient) with $50 \%$ delayed primary healing, especially in earlier operated patients [26].

Van der Meulen et al. moved away from "no touch" approach, and they stated "that there is no need to wait with effective treatment until involution has stopped". They had 9 patients operated with low-flying bird incision (Rethi incision), and with so called „Lapproach", which is Rethi incision extended in cranial direction along the alar fold and nasomaxillary junction. They performed before school age without previous conservative treatment [19].

Pitanguy advocated an elliptical midline incision over the dorsum of the nose that can give good functional results but with obvious midline scar on the back of the nose, and the excision of the dog ear may cause extensions of the incision up into the glabellar region, which may lead to an unsatisfactory aesthetic result $[20,24]$.

Jackson presented excision of a nasal tip hemangioma via open rhinoplasty procedure, with step incision on columella, proceeding on both sides of columella, and continuing just inside the alar rims. The resection of hemangioma and fibrofatty tissue begins between the medial crura and continues upwards over the domes of lower lateral cartilages. The medial crura and the domes of the lower lateral cartilages are approximated with nonapsorbable suture. Intranasal incisions are closed with absorbable suture. A plaster cast was placed for seven days. Care must be taken not to remove too much tissue because with the time and continued involution, this may lead to loss of the nasal projection. The excess skin is allowed to contract over the time (six months) [24].

Denk et al. used the incision made in midline, staring at the tip of the nose, extending the incision superiorly or inferiorly as needed. The mean age at the first operation was 2,2 years [17].

Warren et al. stated that the nose may be divided into topographic subunits (dorsum, tip, alar lobules, side-walls, and soft triangles). There incision were placed along the the lines that separate this subunits. The incision placement in this modified subunit approach to nasal tip hemangiomas was at lateral aspect of the nasal dorsum and carried down around the tip in the declivity medial to the alar lobule and medially into the infratip intercrucial region [15].

Faguer et al. suggest for surgical treatment of nasal hemangiomas transcolumellar lowflying bird (Rethi incision), combined with rim incision to expose alar cartilages [21]. With this technique they manage to excise small and large hemangiomas. Waner at al. stated that this approach is less appropriate for larger hemangioma, because the the incision cannot be extended cranially [13].

McCarthy et al. performed surgical resection of nasal tip hemangioma when the patients was over the age of 3 years for the treatment of lesions that showed no signs of regression over at least a 6 month period. "Open rhinoplasty approach" was used similar to Faguer et al. with transcolumellar incision and marginal "rim incision”. Before this haemostatic 
sutures around the lesion were placed. If there was marked skin excess after redraping, it was resected, sometimes with central wedge excision [14].

Waner et al. proposed modified subunit approach along the contour lines of nasal subunits. Their surgical approach is based on the principles of Burgett and Menick subunit surgery in reconstructive surgery of the nose, but the incision line has been modified to allow better access to all of nasal subunits, and to allow trimming of the excess skin after the hemangioma has been removed. By this technique the lower lateral cartilages are approximated, as well as the medial crura, narrowing the columella to achieve nasal projection. These author avoid placement of in incision in an anterior location due to aesthetic reasons, preserving if it is possible some part of the affected skin which can be treated by laser [13].

Hochman and Mascareno proposed the combination of several treatment modalities. They use classical surgical approach based on already accepted rules, extending the incisions into the alar grooves or vertically along junction of the nasal tip and lobular subunits or even up the midline of the tip [22].

Vlahovic and coworkers use the open rhinoplasty incision for nasal tip, columella and alar subunits hemangioma and circular excision and "purse string suture" for large nasal hemangioma localized on the nasal dorsum with predominant deep component with previous medical (corticosteroid) treatment for large hemangiomas [23].

Eivazi et al. suggested that propranolol should be used as a treatment option for hemangioma of the nasal tip, and if there is indication for surgical treatment (destructive, highly proliferative or otherwise uncontrollable lesions) it should be conventional and made on the basis of the affected regions [25].

Arneja et al. advocate combined medical and surgical approach to treat the "Cyrano" nose. An open rhinoplasty approach with skin resection is the authors preferred technique [27].

Hamou et al. advocate early surgery and the operative technique was chosen based on the size of the lesion and the presence or absence of cutaneous infiltration. [31].

\section{Conclusion}

The optimal treatment approach for nasal hemangiomas remains controversial. Management of nasal hemangiomas involves a combination of serial observation, conservative treatment (propranolol), and surgical therapy.

Serial observation is indicated for small nasal hemangioma, which requires no treatment, but in that way we can give support and counseling to the patient and family. As the results after treatment of hemangioma with propranolol are encouraging, the beta blockers are preferred as the first treatment option for proliferating IHs, and this includes nasal hemangiomas also.

In a rapidly growing hemangioma (precisely the hemangiomas that one would prefer not to operate upon due to increased vascularity and blood loss), the straightforward decision should be to give a trial with propranolol, before embarking upon surgery. If propranolol fails, then surgery becomes next option.

The treatment protocol for propranolol developed by Siegfried at al. to optimize the safety is as follows: baseline echocardiography and 48-hour hospitalization or home nursing visits to monitor vital signs and blood glucose levels, medication is given every 8 hours, with a 
initial dose of $0,16 \mathrm{mg}$ per kilogram of body weight. If the vital signs and glucose levels remain normal, the dose is incrementally doubled to maximum of $0,67 \mathrm{mg}$ per kilogram (to a maximum daily dose of $2.0 \mathrm{mg}$ per kilogram). This therapy should be continued through the proliferative phase of haemangioma growth or until no further improvement occurs. Instead of abrupt discontinuation a gradual tapering of propranolol over 2-3 weeks is recommended. If a rebound effect occurs patients are placed back on propranolol [29].

Different surgical procedures have been suggested for the treatment of nasal hemangiomas depending on the size and location of hemangioma (Fig.2). Surgery had to be performed
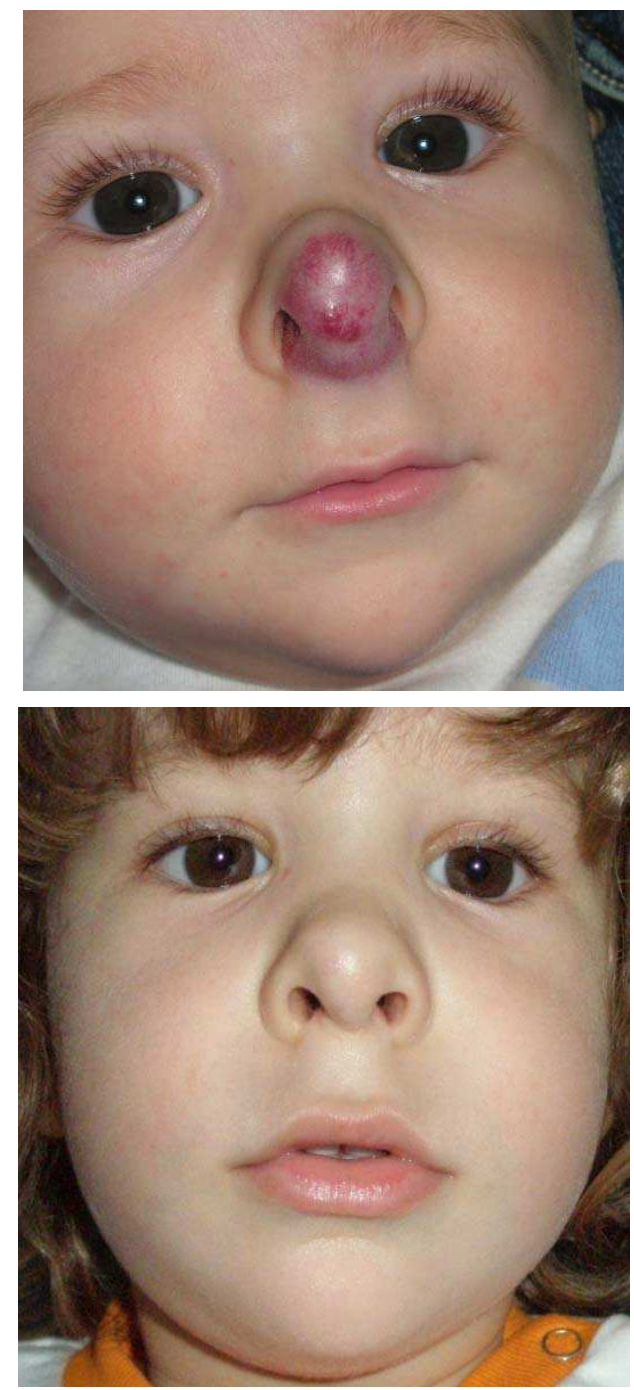

Fig. 2. Preoperative nasal hemangioma and result two years after open rhinotomy excision 
under general anesthesia, with local infiltration of 1:100,000 adrenalin at the incision place. The selection of the optimal surgical approach should be made carefully on the basis of the affected regions. An open rhinoplasty approach, with or without skin resection, should be preferred technique for the lesion that involved nasal tip, columella and alar subunits, and in if wider approach is needed the nasal subunits had to be respected (Fig.3).
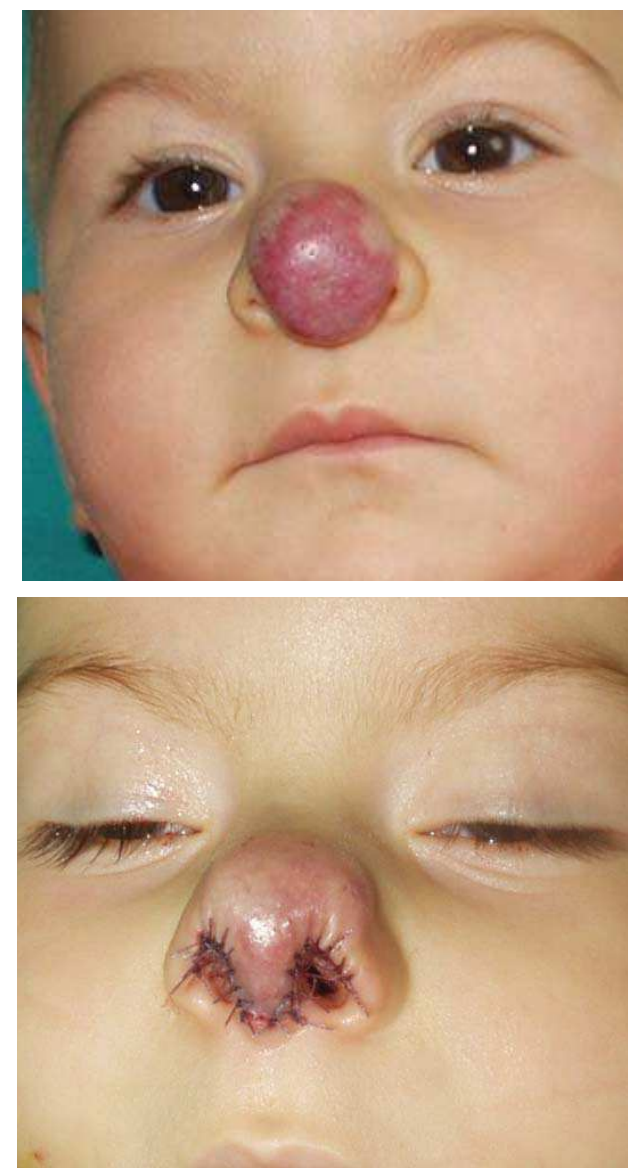

Fig. 3. Intraoperativne result after excision of nasal hemangioma with open rhinoplasty approach

Considering the timing of the surgery, early surgery at the end of the proliferative phase and during second year of life with maximum preservation of the tissue is appropriate because psychosocial, aesthetic and functional problems can be avoided. Surgical removal of nasal hemangioma should be delayed until the hemangioma has stopped proliferating. Surgical treatment during involutional phase is technically easier.

If there are no possibilities for total excision of hemangioma it can be reduced to an acceptable level avoiding destruction of the nasal tissue. 
Subtotal excision for large hemangioma, without all of the affected skin, which will fade in the involutive phase, avoiding visible scars, by placing the incision along the columellar edge and parallel to the nostril is appropriate approach (Fig.4).
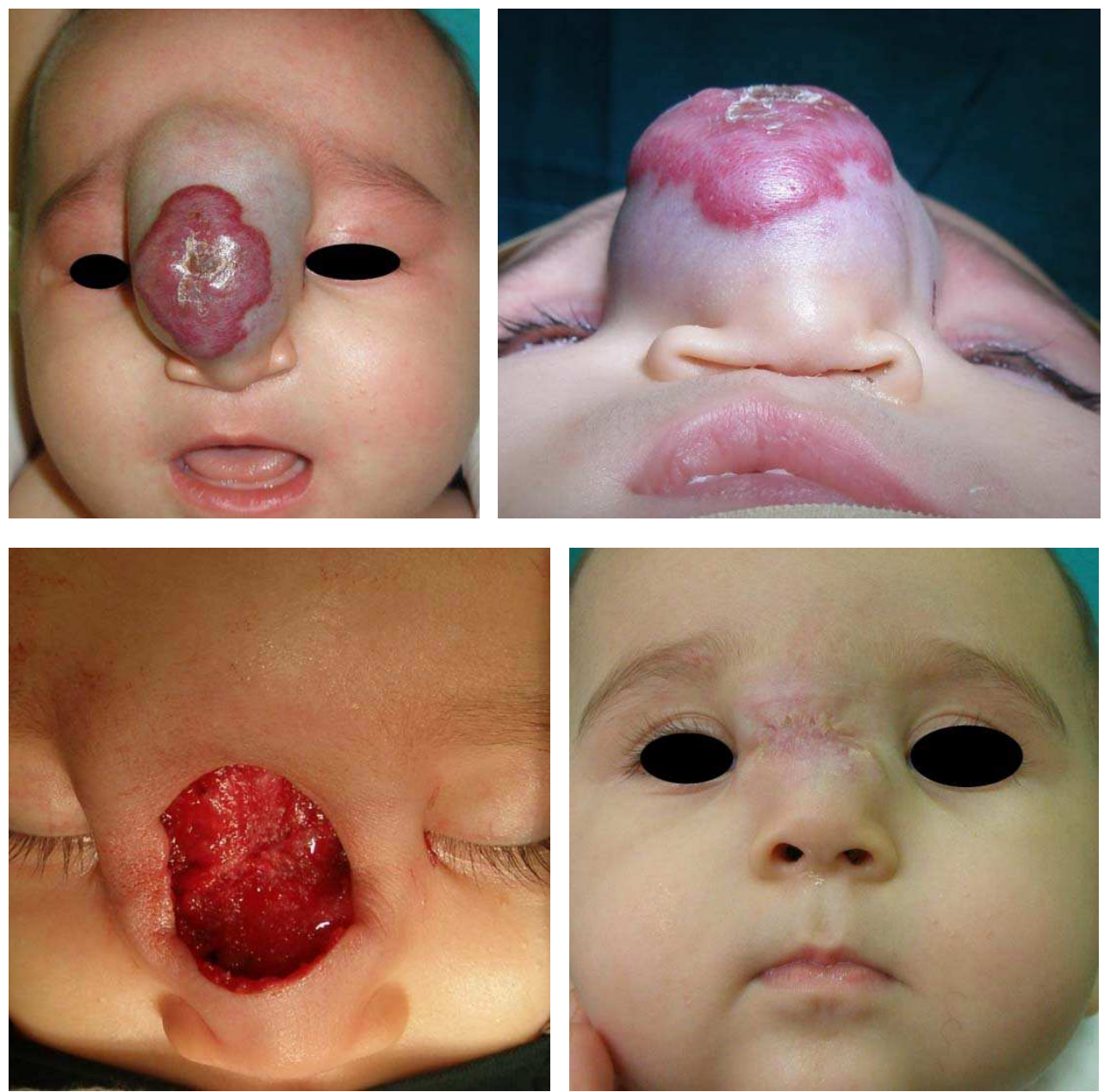

Fig. 4. Circular excision and „purse string suture” technique for large nasal hemangioma

If deep component of hemangioma is predominant, and hemangioma is mostly placed on the nasal dorsum, a circular excision and "purse string suture" technique will be appropriate because of "tissue expander" effect of hemangioma (Fig.5). The scar by this technique is more acceptable comparing to lenticular excision especially for large hemangiomas.

Surgery will retain its importance in cases of non responders to beta blockers, or the theoretical remaining deformity caused by the residual hemangioma or remnant fibrous fatty tissue after hemangiomas regression. 

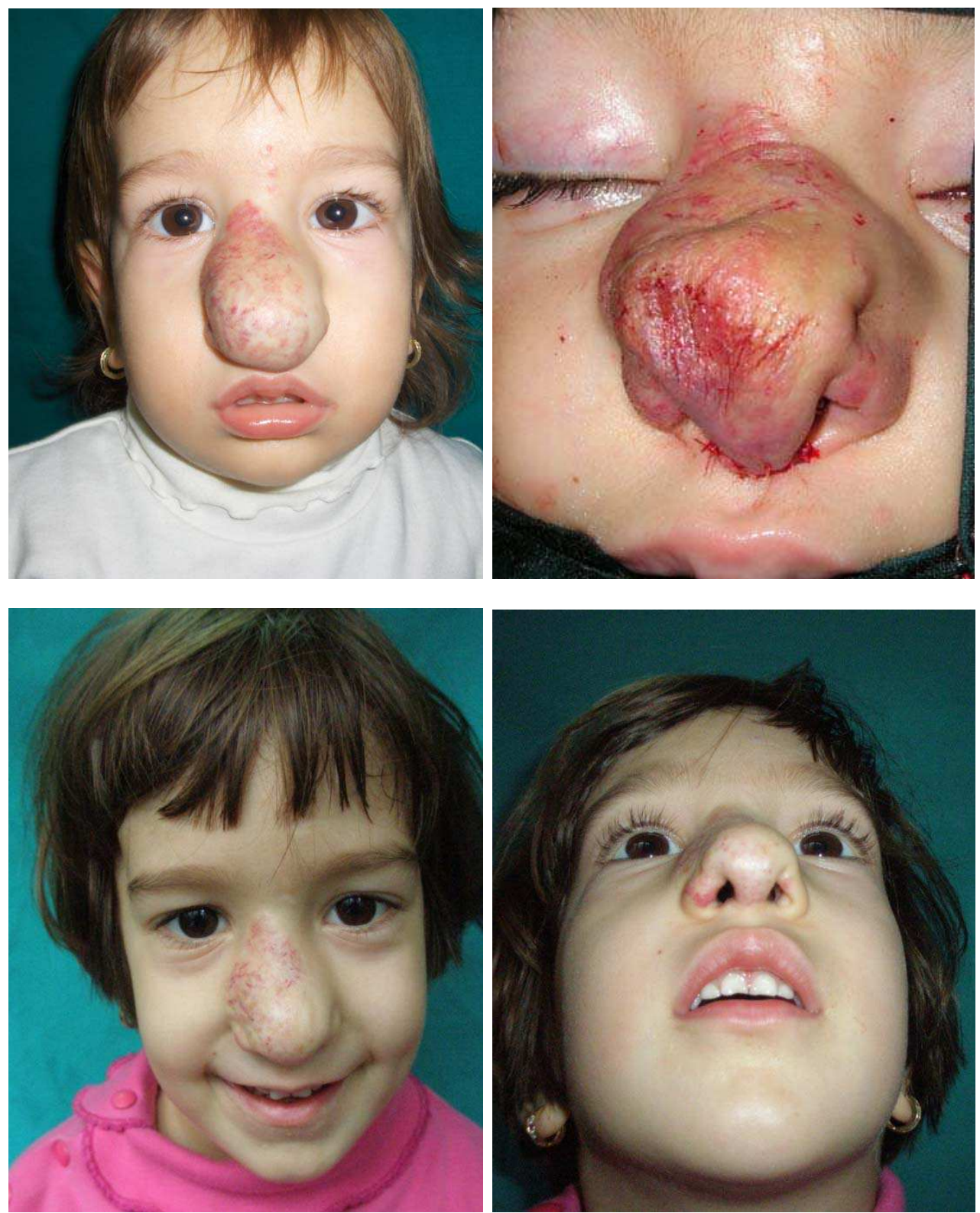

Fig. 5. Excision of large nasal hemangioma with open rhinoplasty approach, minimal tissue removing, result after two years

\section{References}

[1] SJ Fishman, JB Mulliken. Vascular anomalies. Ped Clin N Am 1998;45(6):1455-1477. 
[2] JB Mlliken, J Glowacki. Hemangiomas and vascular malfomations in infants and children:a classification based on endothelial characteristics. Plast Reconstr Surg 1982; 69(3):412-422.

[3] PE North, M Waner, A Mizeracki, MC Mihm. GLUT 1:a newly discovered immunohistochemical marker for juvenile hemangiomas. Hum Pathol 2000;31(1):11-22.

[4] JB Mulliken, O Enjolras. Congenital hemangiomas and infantile hemangioma:missing links. J Am Acad Dermatol 2004;50(6):875-882.

[5] M Waner, PE North, KA Scherer, IJ Frieden, A Waner MC Mihm Jr.The nonrandom distribution of facial hemangimas. Arch Dermatol 2003;139:869-875.

[6] AL Bruckner, IJ Frieden. Infantile hemangiomas. J A Acad Dermatol 2006; 55(4):671-682.

[7] CG Bauland, MA. van Steensel, PM Steijlen, PNMA Rieu, PHM Spauwen. The pathogenesis of hemangiomas:review. Plast Reconstr Surg 2006;117(2):29-35.

[8] JL Tanner, MP Dechert, IJ Frieden. Growing up with a facial hemangioma: parent and child coping and adaptation. Pediatr 1998; 101(3):446-52.

[9] AN Haggstrom, BA Drolet, E Baselga, SL Chamlin, MC Garzon, KA Horii, AW Lucky, AJ Mancini, DW Metry, B Newell AJ Nopper, IJ Frieden. Prospective study of infantile hemangiomas: Clinical characteristics predicting complications and treatment. Pediatr 2006;118(3):882-87.

[10] CG Bauland, JM Smit, R Ketelaars, PNMA Rieu, PHM Spauwen. Management of hemangiomas of infancy: a retrospective analysis and treatment protocol. Scand. J Plast Reconstr Surg Hand Surg. 2008;42:86-91.

[11] M Waner, L Buckmiller, JY Suen. Surgical management of hemangiomas of the head and neck. Oper Tech Otolar-Head Neck Surg 2002;13(1):77-84.

[12] A Vlahovic, R Simic, Dj Kravljanac. Circular excision and purse string suture technique in the management of facial hemangiomas. Int J Ped Otolar 2007;71:1311-1315.

[13] M Waner, J Kastenbaum, K Scherer. Hemangiomas of the nose. Arch Facial Plast Surg. 2008;10(5):329-334.

[14] JG McCarthy, LJ Borud, JS Schreiber. Hemangiomas of the nasal tip. Plast Reconstr Surg 2002;109(1):31-40.

[15] SM Warren, MT Longaker, BM Zide. The subunit approach to nasal tip hemangiomas. Plast Reconstr Surg 2002;109(1):25-30.

[16] S Cho, SY Lee, JH Choi, KJ Sung, KC Moon, JK Koh. Treatment of Cyrano angioma with pulsed dye laser. Dermatol Surg 2001;27:670-72.

[17] MJ Denk, N Ajkay, X Yuan, RS Rosenblum, N Freda, WP Magee. Surgical treatment of nasal hemangiomas. Ann Plast Surg 2002;48:489-495.

[18] L Burgos, JC L Gutierrez, AM Andres, JL Encinas, AL Luis, O Suarez, M Dias, Z Ros. Early surgical treatment in nasal tip hemangiomas: 36 cases review. Cir Pediatr 2007;20(2):83-6.

[19] JC van der Meulen, PhM Gilbert, R. Roddi. Early excision of nasal hemangiomas: The Lapproach. Plast Reconstr Surg 1993;94(3):465-75.

[20] I Pitanguy, BHB Machado, HR Radwanski, NFG Amorim. Surgical treatment of hemangiomas of the nose. Ann Plast Surg 1996; 36(6):586-92.

[21] K Faguer, A Dompmartin, D Labbe, MT Barrellier, D Leroy, J Theron. Early surgical treatment of Cyrano-nose hemangiomas with Rethi incision. B J Plast Surg. 2002; 55:498-53. 
[22] M Hochman, A Mascareno. Management of nasal hemangiomas. Arch. Facial Plast Surg 2005; 7:295-300.

[23] R Simic, A Vlahovic, V Subarevic. Treatment of nasal hemangiomas. Int J Ped Otolar 2009; 73: 1402-1406.

[24] IT Jackson, J Sosa. Excision of nasal tip hemangioma via open rhinoplasty - a skin sparing technique. Eur J Plast Surg 1998;21:265-268.

[25] 25. B Eivazi, HJ Cremer, C Mangold, A Teymoortash, S Wiegand, JAWerner. Hemangiomas of the nasal tip: An approach to a therapeutic challenge. International Journal of Pediatric Otorhinolaryngology 2011; 75: 368-375.

[26] HG Thompson, M Lanigan. The Cyrano nose:a clinical review of hemangioma of the nasal tip. Plast Reconstr Surg 1979;63:155-60.

[27] JS Arneja, H Chim, BA Drolet, AK Gosain. The Cyrano nose:refinements in surgical technique and treatment approach to hemangiomas of the nasal tip. Pl Reconstr Surg 2010;126(4):1291-1299.

[28] C. Leaute-Labreze, E. Dumas de la Roque, T. Hubiche, F. Boralevi. Propranolol for severe hemangiomas of infancy, N. Engl. J. Med 2008; 358: 2649-2651.

[29] AP Zimmermann, S Wiegand, JA Werner, B Eivazi. Propranolol-therapy for infantile haemangiomas: review of literature, Int. J. Pediatr. Otorhinolaryngol. 2010;74: 338342.

[30] IJ Frieden, AN Haggstrom, Drolet BA et al. Infantile hemangiomas: current knowledge, future directions. Proceedings of a research workshop on infantile hemangiomas. Ped Dermatol 2005;22(5):383-406.

[31] C Hamou, PA Diner, P Dalmonte et al. Nasal tip hemangiomas:guidelines for an early surgical approach. J PL Reconstr Aesth Surg 2010;63:934-939.

[32] EC Siegfried, WJ Keenan, S Al-Jureidini. More on propranolol for hemangiomas of infancy. N Engl J Med. 2008;359(26):2846. 


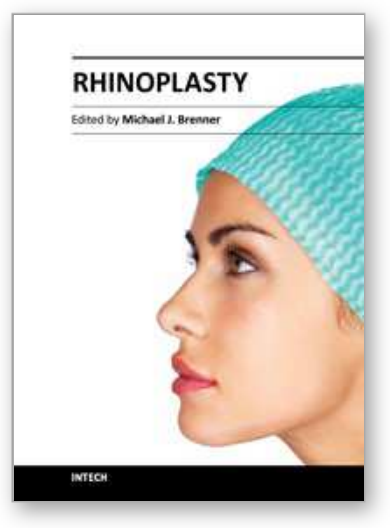

\author{
Rhinoplasty \\ Edited by Dr. Michael Brenner
}

ISBN 978-953-307-849-6

Hard cover, 146 pages

Publisher InTech

Published online 09, December, 2011

Published in print edition December, 2011

Rhinoplasty is one of the defining procedures of plastic and reconstructive surgery. Its roots stem from early efforts in nasal reconstruction to the emergence of modern rhinoplasty. This book describes the latest clinical and research perspectives in rhinoplasty and balances structural correction with aesthetic refinement. With treatises on rhinoplasty from a diverse set of thought leaders from around the world, the collective experience of this books' authors cover cosmetic and reconstructive approaches with a wealth of proven and innovative approaches ranging from minor refinement to major reconstruction. This diversity reflects the inherent complexity of the art and science of rhinoplasty. Discussion of structural approaches is balanced by consideration of judicious resection and refinement. The overarching goal is to instill an understanding of the subtleties of nasal structure and how the natural complexities of nasal anatomy can be adapted to maximize both function and natural appearance.

\title{
How to reference
}

In order to correctly reference this scholarly work, feel free to copy and paste the following:

Aleksandar Vlahovic (2011). Surgical Management of Nasal Hemangiomas, Rhinoplasty, Dr. Michael Brenner (Ed.), ISBN: 978-953-307-849-6, InTech, Available from:

http://www.intechopen.com/books/rhinoplasty/surgical-management-of-nasal-hemangiomas

\section{INTECH}

open science | open minds

\author{
InTech Europe \\ University Campus STeP Ri \\ Slavka Krautzeka 83/A \\ 51000 Rijeka, Croatia \\ Phone: +385 (51) 770447 \\ Fax: +385 (51) 686166 \\ www.intechopen.com
}

\author{
InTech China \\ Unit 405, Office Block, Hotel Equatorial Shanghai \\ No.65, Yan An Road (West), Shanghai, 200040, China \\ 中国上海市延安西路65号上海国际贵都大饭店办公楼405单元 \\ Phone: +86-21-62489820 \\ Fax: $+86-21-62489821$
}


(C) 2011 The Author(s). Licensee IntechOpen. This is an open access article distributed under the terms of the Creative Commons Attribution 3.0 License, which permits unrestricted use, distribution, and reproduction in any medium, provided the original work is properly cited. 